\title{
Efficacy of counseling for cervical cancer screening and protective procedures on Saudi women's health beliefs and practice
}

\author{
Soliman Aziza ${ }^{1}$, Amany S. Badawy ${ }^{* 1,2}$, Fouad Abeer ${ }^{1}$ \\ ${ }^{1}$ College of Nursing, King Saud University, Riyadh, Saudi Arabia \\ ${ }^{2}$ College of Nursing, Zagazig University, Zagazig, Egypt
}

Received: April 9, 2016

DOI: $10.5430 /$ jnep.v7n2p117
Accepted: August 28, $2016 \quad$ Online Published: October 17, 2016

URL: http://dx.doi.org/10.5430/jnep.v7n2p117

\begin{abstract}
Background: Cervical cancer is the second most common cancer of women in the world, and it becomes a major cause of cancer mortality in low-income countries due to inadequate use of screening services. Currently, little is known regarding cervical cancer incidence in Arabic countries. In the Kingdom of Saudi Arabia, cervical cancer occurs in 4.1/100,000 females in the population. It accounts for $7 \%$ of all newly diagnosed cancers in females, and is the eighth leading cause of cancer deaths in Saudi females. Although, the Pap smear test is available at the health setting, the community health awareness program is not well established. Over the past 2 decades, the number of cases of cervical cancer has been increasing due to lack of awareness about Pap smear testing.
\end{abstract}

Objective: The objective of the study was to evaluate the efficacy of counseling about cervical cancer in changing Saudi women's beliefs and practices toward screening and protective procedures.

Methods: A Quasi-experimental design that included 100 Saudi women who were administered a structured questionnaire and a Health Belief Model Scale for Cervical Cancer and Pap Smear Test prior to receiving counseling and follow up.

Results: Before counselling, Chi Square test showed a statistical significant $11.649(p=.02)$ in relation to the symptoms of cervical cancer. As regarding the methods of cervical cancer diagnosis $45.0 \%$ agreed that a checkup should be done every year for early diagnosis and $63.0 \%$ believed that early marriage and null-gravidity are leading factors for cervical cancer, while $32.0 \%$ and $37.0 \%$ agree with lack of community awareness about cervical cancer and neglect of abnormal genital symptoms. A highly statistical significance with $(p=.005)$ in relation to the methods of diagnosis for cervical cancer. 66.0\% know about Pap smear testing, while $67.0 \%$ had no previous Pap smear examination. The knowledge about HPV vaccination was very low (94.0\%) don't know about HPV vaccination. Post counselling protective practice from cervical cancer showed a high significance related to Pap smear $(p=.001)$ and HPV vaccine, vaginal hygiene care and balanced diet $(p=.05)$. There was no statistical significance in relation to self-examination of the vulva $(p=.32)$.

Conclusions: Primarily beliefs and practices among women in the target group should be evaluated to increase their participation in cervical cancer screening and to develop effective education strategies. There is a need to educate the general community about the disease and its prevention.

Key Words: Cervical cancer screening, Pap-smear, Behaviors, Beliefs

*Correspondence: Amany S. Badawy; Email: dramanys@yahoo.com; Address: College of Nursing, Zagazig University, Zagazig, Egypt. 


\section{INTRODUCTION}

Globally, cervical cancer is one of the most common cancers in women, with an estimate of 440,000 new cases annually, and $80 \%$ of these cases occurring in developing and undeveloped countries due to inadequate use of the screening services. ${ }^{[1,2]}$ All sexually active women are at risk for the development of cervical cancer. ${ }^{[3]}$ Human papillomavirus (HPV) infection is responsible for more than $90 \%$ of the cases of invasive cervical cancer worldwide, and it is related to $80 \%$ of pre-cancerous changes in the cervix. ${ }^{[1]}$ The most notable risk factor for cervical cancer is failure to undergo screening, which accounts for roughly half of women diagnosed with cervical cancer. Other risk factors include smoking, immunosuppression from any cause including HIV infection, long-term use of oral contraception, co-infection with Chlamydia, parity, prior cervical cancer, and genetic polymorphisms affecting the entry of HPV DNA into cervical cells. ${ }^{[4]}$

Cervical cancer can be prevented when it is detected and treated prior to the pre-invasive stage. This can be accomplished through scheduled Pap smear screening for cervical cancer. The screening programs for early detection and treatment of cervical cancer haves significantly reduced the morbidity and mortality of these diseases. ${ }^{[5,6]}$ Two vaccines are now available for primary prevention. They generate neutralizing antibodies to HPV capsid protein. The vaccines have been shown to confer nearly 100 per cent protection against cervical pre-cancers and genital warts caused by HPV types. Vaccination and screening, which are complementary and synergistic, now constitute the new paradigm for prevention of this disease. ${ }^{[7]}$

Regular Papanicolaou's (PAP) smear screening has reduced the incidence of mortality from cervical cancer tremendously. This simple screening test can detect pre-invasive, and invasive disease process in very early stages, at which it can be prevented, treated, and cured. This screening method has been proven to reduce the incidence and mortality from cervical cancer up to $80 \%$ in developed countries. Therefore, this test is recommended for all sexually active females worldwide. ${ }^{[8,9]}$

The role of counseling in providing psychosocial support and encouragement for behavior change has proved to be immense value. Counseling is considered very important in order to achieve the purpose of screening. Providing information on cervical cancer in the community and in health services is vital to raising awareness and reducing illness and death. ${ }^{[10]}$ Behavioral intention can be improved through counseling. A woman's behavioral intention is based on her attitude toward screening, her belief as well as the support of the people around a woman regarding the need and benefits of screening. To participate in any screening program, the woman has to be ready. If she is not ready to be screened, she will not present herself for screening as counseling sessions helps in preparing women for screening. ${ }^{[1]}$

The Health Belief Model (HBM) is based on the concept that the relationship between the individuals beliefs and their abilities to be involved in certain health behaviors influence their health and affect their lives. This aid the health care provider's health plans toward increase the individuals in taking preventive measures. The women in the developing countries in need to recognize the importance of early detection and screening for cervical cancer as they are at risk to silently endure the disease that may become a serious health problem if the women did not perceived that they are at risk and be motivation toward changing their believes and perceive the benefits for early detection and treatment. ${ }^{[12]}$

The major barriers for taking the preventive measures are low education specially health education and poverty. It is mandate planed health education that address the biological structure and function of the female's reproductive organs, the causes of cervical cancer, the life style relation to the incidence of the disease, and how it can be prevented. Also, emphasis on motivation for screening to help in early detection and proper treatment should be considered. Education should focus on the myths that may affect cultural health beliefs associated with cervical cancer. ${ }^{[13]}$

Changing the health believes is a challenging for health care providers with any population group. However, the HBM can be used as a guide in enhancing the women's awareness toward cervical cancer, sittings that providing screening tools if there are well established health policies that address social and cultural beliefs and attitudes. ${ }^{[14]}$

\subsection{Significance of the problem}

In the Kingdom of Saudi Arabia, the incidence of cervical cancer is at 1.9 cases per 100,000 women, and accounting for $2.2 \%$ of diagnosed cases of cancer in Saudi women and is the thirteenth most frequent according to the 2007 Saudi cancer registry report. ${ }^{[15]}$ While cervical cancer had been reported in a study conduct in 2009 that it occurs in 4.1/100,000 females in the population and it accounts for $7 \%$ of all newly diagnosed cancers in females, and is the eighth leading cause of cancer death in Saudi females that ${ }^{[16]}$ considering both studies, the incidence rate in Saudi Arabia is one of the lowest in the world. Although cervical cancer is both preventable and curable, as an intensive screening program for cervical cancer is well established through HPV vaccine, and the availability of the Pap smear test among different health 
sectors, most women in Saudi Arabia present at advanced stages that require extensive chemo-radiation therap. It is mandatory to address the knowledge, attitudes and beliefs of the women about cervical cancer screening. There are little published data on the efficacy of counselling regarding preventive measures of cervical cancer globally and non in Saudi Arabia.

\subsection{Aim of the study}

To evaluate the efficacy of counseling about cervical cancer in Changing Saudi women's beliefs and practices toward screening and protective procedures.

Research questions: (1) What are the Saudi women knowledge and believes regarding cervical cancer? (2) Dose counselling aid to change the false beliefs and enhance health behaviors for screening and protective measures of cervical cancer?

\section{SubJECTS AND METHOdS}

\subsection{Study design and sampling method}

The study was designed as a quiz-experimental type to evaluate the efficacy of counseling in changing Saudi women's beliefs and practices toward screening and protective procedures of cervical cancer. The study was performed in two Holy Quran centers in Riyadh City between September 2014 and April 2015. Women included in the study were selected from a simple random sampling method for 100 Saudi married, widowed or divorced women.

\subsection{Tools of data collection}

Data were collected by means of a structured questionnaire of closed ended. Questions that was developed by the researchers as a result of the literature review covering sociodemographic data, concepts about cervical cancer, risk factors, practices for screening and prevention using a modified Health Belief Model Scale for Cervical Cancer and Pap Smear Test form. This scale was developed by adapting Champion's Breast Health Survey ${ }^{[17,18]}$ on breast cancer screening. The Health Belief Model provided the theoretical guidance for the development of the research questions. The Scale for Cervical Cancer and the Pap smear is a Likert type instrument scoring from 1 to 3 where 1 point to 'disagree', 2 points to 'neutral' and 3 points to 'agree'. Cronbach alpha reliability coefficients for the five subscales ranged from Pap smear benefit/health motivation 0.86; Pap smear barriers 0.82 ; seriousness 0.78 ; susceptibility 0.78 ; and health motivation 0.62 .

\subsection{Process of counseling}

The women were counseled after the interview. Individualized and grouped counselling strategies were used. The counseling process involves providing information on cervical cancer which includes the causes, risk factors, and methods of screening especially vualval self-examination, Papanicolau smear test as the common screening method and offering HPV vaccine in the health setting providing these services.

\subsection{Post counseling follow-up}

Evaluating the changes in health behaviors and practices toward preventive measures of cervical cancer was carried for four months post counselling.

\subsection{Ethical consideration}

After institutional approval had been obtained, data were collected. It was explained to the participants that they had the right to withdraw from the investigation and the information would be kept strictly confidential.

\section{RESUlT}

The majority of the studied sample finds that $45 \%$ was aged 30 to 40 years, $36 \%$ was aged of 20 to 29 years, $18 \%$ of the study sample their age was more than 40 years aged, and only $1 \%$ were less than 20 years old. Based on the educational level of the sample, 54\% was university education, $20 \%$ was primary and preparatory education, and $7 \%$ was higher education. The majority of the study sample (86\%) were married, As regard to the age at marital, it was found that $55 \%$ of the study sample married at age 20-24 years, $17 \%$ was married at age 25-30 years with Mean $17.73 \pm$ SD 4.679. Also this table shows that $47 \%$ of the study sample had married more than ten years (see Table 1).

Regarding reproductive health history, the results revealed that the mean age at menarche $13.03 \pm 2.012$, menstrual duration $6.36 \pm 1.396$, the mean age at 1 st delivery $18.6 \pm$ 4.032 , while the mean number of delivery $1.39 \pm 0.702$. The majority of the study sample does not terminated pregnancies $64.0 \%$, while $31.0 \%$ were terminated. Most of the study sample $(74.0 \%)$ had regular menstruation. As regarding the previous mode of delivery the majority of the sample $65.0 \%$ had normal vaginal delivery, while $9 \%$ had caesarean section. Regarding the bleeding occur during labour $79.0 \%$ no bleeding and $21.0 \%$ had bleeding during labour. $60.0 \%$ of the study sample had no genital tract infection. Most of the study sample $44.0 \%$ used oral contraceptive methods, $20.0 \%$ used IUD method, while $12.0 \%$ never used a contraceptive method. Chi Square showed a statistically significant use of contraceptive methods $12.760(p=.067)$ (see Table 2). 
Table 1. Distribution of the study sample according to Socio- demographic data

\begin{tabular}{llll}
\hline Items & Frequency $\mathbf{~ 1 0 0}$ & Percent (\%) & Mean \pm SD \\
\hline Age & 1 & & \\
$<20$ & 36 & 1.0 & $28.0 \pm 0.739$ \\
$20-29$ & 45 & 36.0 & \\
$30-40$ & 18 & 45.0 & \\
$>40$ & & 18.0 & \\
Years of marriage & 6 & 6.0 & $3.14 \pm 0.954$ \\
$\quad<$ one year & 21 & 21.0 & \\
$1-4$ yrs. & 26 & 26.0 & \\
$5-9$ yrs. & 47 & 47.0 & $17.73 \pm 4.679$ \\
$>10$ yrs. & 28 & 28.0 & \\
Age at married & 55 & 55.0 & Chi Square \\
14-19 & 17 & 17.0 & \\
$20-24$ & Frequency $=\mathbf{1 0 0}$ & Percent (\%) & \\
$25-30$ & & & $\chi^{2}=7.900$ \\
\hline & 20 & 20.0 & $p=.100$ \\
\hline Level of education & 19 & 19.0 & \\
Primary \&Preparatory & 54 & 54.0 & $\chi^{2}=126.32$ \\
Secondary & 7 & 7.0 & $p=.05$ \\
University & & & \\
$\quad$ Higher education & 86 & 86.0 & \\
Marital status & 12 & 12.0 & \\
Married & 2 & 2.0 & \\
Divorced & & & \\
Widow & & & \\
\hline
\end{tabular}

Table 3 shows the women's belief regarding symptoms \& methods of diagnosis for cervical cancer before counselling. The majorities of the study sample $29.0 \%$ agree with the symptoms of vaginal secretion, $8.0 \%$ agree with no symptoms. $27.0 \%$ mutual with no symptoms, while $12.0 \%$ of the sample mutual with the symptoms of menstruation discomfort. $65.0 \%$ disagree with abdominal Pain \& no symptoms. Furthermore $56.0 \%$ disagree with the vaginal secretion. Chi Square test showed a statistical significant $11.649(p=$ $.02)$ in relation to the symptoms of cervical cancer before counselling. As regarding the methods of cervical cancer diagnosis before counselling $45.0 \%$ agree with the checkup should be done every year for early diagnosis, while $11.0 \%$ agree with checkup is important for diagnosis. in addition the method of cervical cancer diagnosis before counselling $35.0 \%$ mutual with the methods for cervical cancer detection only $2.0 \%$ of the study sample mutual with the women can recognized the symptoms of cervical cancer. $78.0 \%$ of the study sample disagree with the women can recognized symptoms of cervical cancer, while $34.0 \%$ disagree with Pap smear is a method for diagnosis. A highly statistical significant $40.602(p=.005)$ in relation to the methods of diagnosis for cervical cancer before counselling.

Regarding women's beliefs factors lead to cervical cancer before counseling. Table 4 shows that $63.0 \%$ of the study sample agree with early marriage and null-gravidity, while
$32.0 \%$ \& $37.0 \%$ agree with lack of community awareness about cervical cancer \& neglect of abnormal genital symptoms, $57.0 \%$ agree with multi-gravidity and obesity. Regarding lack of healthy foods rich in fibers $56.0 \%$ agree, while $51.0 \%$ agree with heredity factors. $37.0 \%$ of the study sample agree with sexual transmitted disease \& $36.0 \%$ vaginal infection. As regarding agree with no periodical examination $43.0 \%$, while $39.0 \%$ agree with fear from discovery of the disease. Table 4 also shows $33.0 \%$ of the study sample mutual with multi-gravidity, while $26.0 \%$ null-gravidity. In addition mutual related to early marriage $29.0 \%$ and $27.0 \%$ for late marriages. Only $12.0 \%$ of the study sample mutual with the lack of knowledge about the causes and methods of diagnosis, while $13.0 \%$ lack of community awareness about cervical cancer. Furthermore, vaginal infection and heredity factors $15 \%$ mutual. Regarding sexual transmitted disease $10.0 \%$ the mutual, while $9.0 \%$ neglect of abnormal genital symptoms. As regarding these factors $55.0 \%$ of the study sample disagree with lack of community awareness about cervical cancer, while $53.0 \%$ related to sexual transmitted disease. The majority of the study sample disagree $43.0 \%$ lack of knowledge about the causes and methods of diagnosis, $54.0 \%$ neglect of abnormal genital symptoms $42.0 \%$ no periodical examination $49.0 \%$ vaginal infection \& $37.0 \%$ Fear from discovery of the disease. Only $8.0 \%$ of the study sample disagree with the early marriage, while $12.0 \%$ late marriages $10.0 \%$ Multi-gravidity \& $11.0 \%$ null-gravidity. 
Table 2. Frequency distribution of the study sample according to reproductive health history

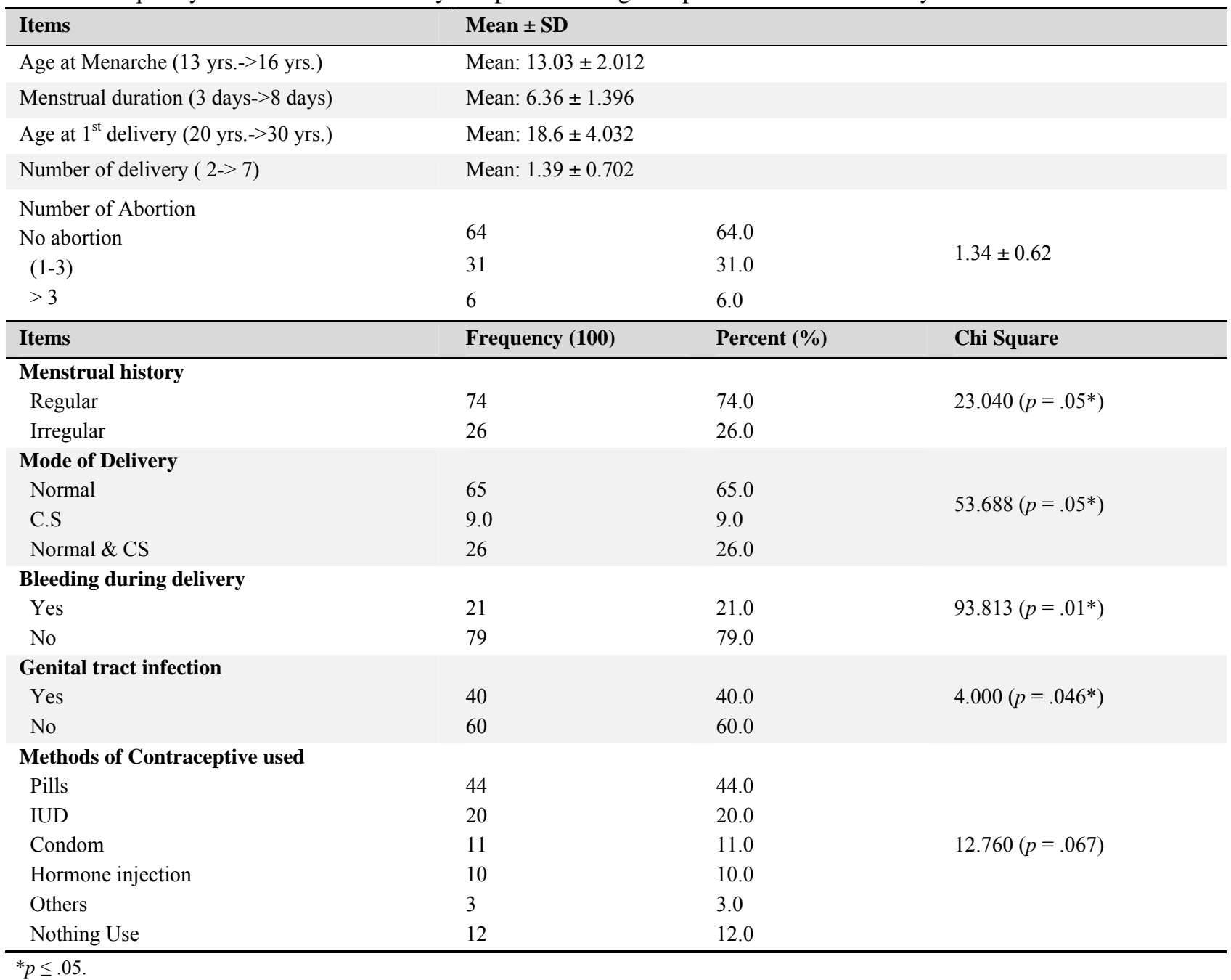

Table 3. Women's beliefs regarding symptoms \& methods of diagnosis for cervical cancer before counselling

\begin{tabular}{|c|c|c|c|c|c|c|c|}
\hline \multirow{2}{*}{ Items } & \multicolumn{2}{|l|}{ Agree } & \multicolumn{2}{|l|}{ Mutual } & \multicolumn{2}{|l|}{ Disagree } & \multirow{2}{*}{ Chi Square } \\
\hline & $\mathbf{N}=100$ & $\%$ & $\mathrm{~N}=100$ & $\%$ & $\mathbf{N}=100$ & $\%$ & \\
\hline \multicolumn{8}{|l|}{ Symptoms } \\
\hline Vaginal Bleeding & 23 & 23.0 & 17 & 17.0 & 60 & 60.0 & \multirow{5}{*}{$\begin{array}{l}11.649 \\
\left(p=.02^{*}\right)\end{array}$} \\
\hline Vaginal Secretion & 29 & 29.0 & 15 & 15.0 & 56 & 56.0 & \\
\hline Menstruation discomfort & 26 & 26.0 & 12 & 12.0 & 62 & 62.0 & \\
\hline Abdominal Pain & 16 & 16.0 & 19 & 19.5 & 65 & 65.0 & \\
\hline No symptoms & 8 & 8.0 & 27 & 27.0 & 65 & 65.0 & \\
\hline \multicolumn{7}{|l|}{ Method of diagnosis } & \multirow{8}{*}{$\begin{array}{l}40.602 \\
\left(p=.005^{* *}\right)\end{array}$} \\
\hline There are methods for cervical cancer detection. & 15 & 15.0 & 35 & 35.0 & 50 & 50.0 & \\
\hline Detection by periodical medical examination. & 23 & 23.0 & 16 & 16.0 & 61 & 61.0 & \\
\hline Appearances of abnormal symptoms lead to diagnosis. & 17 & 17.0 & 17 & 17.0 & 66 & 66.0 & \\
\hline Checkup is important for diagnosis. & 11 & 11.0 & 30 & 30.0 & 59 & 59.0 & \\
\hline Checkup should be done every year for early diagnosis. & 45 & 45.0 & 12 & 12.0 & 43 & 43.0 & \\
\hline Women can recognized symptoms of cervical cancer. & 20 & 20.0 & 2 & 2.0 & 78 & 78.0 & \\
\hline Pap smear is a method for diagnosis. & 32 & 32.0 & 34 & 34.0 & 34 & 34.0 & \\
\hline
\end{tabular}

*Significant, **H Significant. 
Table 4. Women's beliefs regarding factors lead to cervical cancer before counseling

\begin{tabular}{|c|c|c|c|c|c|c|c|}
\hline \multirow{2}{*}{ Factors lead to cancer cervix } & \multicolumn{2}{|l|}{ Agree } & \multicolumn{2}{|l|}{ Mutual } & \multicolumn{2}{|c|}{ Disagree } & \multirow{2}{*}{ Chi Square } \\
\hline & $\mathbf{N}=100$ & $\%$ & $\mathbf{N}=100$ & $\%$ & $\mathbf{N}=\mathbf{1 0 0}$ & $\%$ & \\
\hline Heredity factors & 51 & 51.0 & 15 & 15.0 & 34 & 34.0 & \multirow{10}{*}{$\begin{array}{l}32.098 \\
p=.001^{* *}\end{array}$} \\
\hline Vaginal infection & 36 & 36.0 & 15 & 15.0 & 49 & 49.0 & \\
\hline Sexual Transmitted Disease & 37 & 37.0 & 10 & 10.0 & 53 & 53.0 & \\
\hline No periodical examination & 43 & 43.0 & 15 & 15.0 & 42 & 42.0 & \\
\hline Multi-gravidity & 57 & 57.0 & 33 & 33.0 & 10 & 10.0 & \\
\hline Fear from discovery of the disease & 39 & 39.0 & 24 & 24.0 & 37 & 37.0 & \\
\hline Neglect of abnormal genital symptoms & 37 & 37.0 & 9 & 9.0 & 54 & 54.0 & \\
\hline Late marriages & 61 & 61.0 & 27 & 27.0 & 12 & 12.0 & \\
\hline Early marriage & 63 & 63.0 & 29 & 29.0 & 8 & 8.0 & \\
\hline Null-gravidity & 63 & 63.0 & 26 & 26.0 & 11 & 11.0 & \\
\hline Obesity & 57 & 57.0 & 18 & 18.0 & 25 & 25.0 & $7.130 p=.129$ \\
\hline Lack of healthy foods rich in fibers & 56 & 56.0 & 19 & 19.0 & 25 & 25.0 & \multirow{3}{*}{$\begin{array}{l}21.369 \\
p=.002^{* *}\end{array}$} \\
\hline Lack of knowledge about the causes and methods of diagnosis & 45 & 45.0 & 12 & 12.0 & 43 & 43.0 & \\
\hline Lack of community awareness about cervical cancer & 32 & 32.0 & 13 & 13.0 & 55 & 55.0 & \\
\hline
\end{tabular}

Table 5. Women's knowledge about Pap smear and HPV vaccination before counseling

\begin{tabular}{|c|c|c|c|}
\hline Item/Pap Smear & Frequency $(\mathrm{N}=100)$ & Percent (\%) & Chi Square \\
\hline \multicolumn{4}{|l|}{ Know about Pap smear } \\
\hline Yes & 66 & 66.0 & \multirow[t]{2}{*}{$5.863(p=.439)$} \\
\hline No & 34 & 34.0 & \\
\hline \multicolumn{4}{|l|}{ Previous Pap Smear examination } \\
\hline Yes & 33 & 33.0 & \multirow[t]{2}{*}{$6.880\left(p=.032^{*}\right)$} \\
\hline No & 67 & 67.0 & \\
\hline \multicolumn{4}{|l|}{ Time for Pap Smear } \\
\hline Before disease detection & 29 & 29.0 & \multirow{3}{*}{$0.178(p=.673)$} \\
\hline After disease detection & 5 & 5.0 & \\
\hline I don’t Know & 66 & 66.0 & \\
\hline \multicolumn{4}{|l|}{ Reason for Pap Smear } \\
\hline Referral from doctors. & 48 & 48.0 & \multirow{3}{*}{$6.880(p=.032)$} \\
\hline Early detection \& Follow up & 32 & 32.0 & \\
\hline Others & 20 & 20.0 & \\
\hline \multicolumn{4}{|l|}{ Sitting for Pap smear procedure } \\
\hline Primary health center & 5 & 5.0 & \multirow{4}{*}{$6.580(p=.087)$} \\
\hline Hospital Gynecological clinic & 69 & 69.0 & \\
\hline Privet clinic & 10 & 10.0 & \\
\hline I don’t Know & 16 & 16.0 & \\
\hline HPV vaccination & Frequency $(\mathrm{N}=100)$ & Percent (\%) & Chi Square \\
\hline \multicolumn{4}{|l|}{ Know about HPV vaccination } \\
\hline Yes & 6 & 6.0 & \multirow[t]{2}{*}{$4.178(p=.0167)$} \\
\hline No & 94 & 94.0 & \\
\hline \multicolumn{4}{|l|}{ Previous HPV immunization } \\
\hline Yes & 4 & 4.0 & \multirow[t]{2}{*}{$14.303\left(p=.005^{* *}\right)$} \\
\hline No & 96 & 96.0 & \\
\hline \multicolumn{4}{|l|}{ Sitting for Vaccination } \\
\hline Primary health center & 10 & 10.0 & \multirow{4}{*}{$6.580(p=.087)$} \\
\hline Hospital Gynecological clinic & 75 & 75.0 & \\
\hline Privet clinic & 9 & 9.0 & \\
\hline I don't Know & 6 & 6.0 & \\
\hline
\end{tabular}

*Significant, **H Significant. 
Women's knowledge about Pap smear and HPV vaccination before counseling. 66.0\% know about Pap smear, while 67.0\% had no Previous Pap Smear examination. Regarding the Time for Pap smear $66.0 \%$ don't know, while $5.0 \%$ after disease detection. The reason for Pap smear (48.0\%) referral from doctors. As regarding the Sitting for Pap smear procedure $69.0 \%$ of the study sample had knowledge in the hospital (Gynecological clinic) only 5.0\% had knowledge done in primary health center. This table also shows the knowledge about HPV vaccination (94.0\%) don't know about HPV vaccination. Chi square test shows a statistical significant in relation to the knowledge about HPV vaccination. 4.178 ( $p$
$=.0167)$. In relation to Previous HPV immunization $96.0 \%$ had no previous immunization, a highly statistical significant $14.303(p=.005)$. Regardless the sitting for vaccination $75.0 \%$ in the hospital (Gynecological clinic), while $6.0 \%$ don't Know (see Table 5).

Table 6 represents the Women's beliefs about Factors help early diagnosis of cervical cancer post counseling. Results of the study revealed that $42 \%$ reported more than one factors help them, only $3 \%$ from the study sample history of the disease in the family. On the other hand the mass media and awareness for early detection of the cervical cancer $18 \%$ \& $10 \%$ respectively.

Table 6. Women's beliefs about Factors help early diagnosis of cervical cancer post counseling

\begin{tabular}{lll}
\hline Items & Frequency $(\mathbf{N}=\mathbf{1 0 0})$ & Percent $\mathbf{( \% )}$ \\
\hline Higher educational level for women & 9 & 9.0 \\
Reading \& Information. & 9 & 9.0 \\
History of the disease in the family & 3 & 3.0 \\
Priorities of health of the women & 9 & 9.0 \\
Awareness for early detection of disease & 10 & 10.0 \\
Mass media & 18 & 18.0 \\
More than one & 42 & 42.0 \\
\hline
\end{tabular}

Regarding post counselling protective practice from cervical cancer a high significant was observed related to Pap smear $(p=.001)$. Also this table shows a statistical significant observed for take vaccine, vaginal hygiene care and balanced diet $(p=.05)$. A highly statistical significant observed re- garding use of contraceptive as prescribed and treatment of genital tract infections ( $p=.001 \& p=.005$ respectively). No statistical significant in relation to self-examination for vulva $p=.32$ (see Table 7).

Table 7. Women's Protective practices from cervical cancer post counseling

\begin{tabular}{|c|c|c|c|c|c|c|c|}
\hline \multirow{2}{*}{ Protective practice } & \multicolumn{2}{|l|}{ Done } & \multicolumn{2}{|c|}{ Not done } & \multicolumn{2}{|c|}{ Will be done } & \multirow{2}{*}{ Chi Square } \\
\hline & $\mathbf{N}=\mathbf{1 0 0}$ & $\%$ & $\mathbf{N}=\mathbf{1 0 0}$ & $\%$ & $\mathbf{N}=\mathbf{1 0 0}$ & $\%$ & \\
\hline Self-examination for vulva & 81 & 81.0 & 4 & 4.0 & 15 & 15.0 & $72.203 p=.32$ \\
\hline Pap Smear & 45 & 45.0 & 11 & 11.5 & 44 & 44.0 & $14.303 p=.001^{* *}$ \\
\hline Take Vaccine & 49 & 49.0 & 7 & 7.0 & 44 & 44.0 & $66.345 p=.05^{*}$ \\
\hline Vaginal hygiene care & 71 & 71.0 & 6 & 6.0 & 21 & 21.0 & $89.517 p=.05^{*}$ \\
\hline Balanced Diet & 49 & 49.0 & 8 & 8.0 & 43 & 43.0 & $90.489 p=.05^{*}$ \\
\hline Use contraceptive as Prescribed & 61 & 61.0 & 9 & 9.0 & 30 & 30.0 & $41.060 p=.001$ \\
\hline Treatment of genital infections & 59 & 59.0 & 14 & 14.0 & 27 & 27.0 & $109.991 p=.005^{*}$ \\
\hline
\end{tabular}

*Significant, **H Significant.

\section{Discussion}

Cervical Cancer of the cervix is the second most common cancer among women worldwide. Estimated 529,409 new cases, $86 \%$ of the cases occur in developing countries, representing $13 \%$ of female cancers. Saudi Arabia has a population of 6.51 million women ages 15 years and older. Current

Published by Sciedu Press estimates indicate that every year 152 women are diagnosed with cervical cancer and 55 die from the disease. Cervical cancer is the 8th most frequent cancer among women between 15 and 44 years of age. ${ }^{[16,17]}$ The age of women included in the current study was between 20-40 years old and $40 \%$ of them had a history of genital tract infections and 
the mean of age at 1 st delivery of $18.6 \pm 4.032$, as well $44 \%$ were oral contraceptive users, which may put them at risk for cervical cancer. Also, the results of the present regarding the women's beliefs about symptoms \& factors lead to cervical cancer revealed a higher misconception among them. This is coincide with the studies carried in Turkey and US that found a relatively low level of knowledge about cervical cancer and cervical cancer screening among women of different cultures. ${ }^{[2,18,19]}$ The frameworks of many theories and models of behavior suggest that beliefs have a significant role in explaining and determining health behavior. In the last decades, among different behavioral theories, the Health Belief Model (HBM) has been considered to be one of the most representative ones due to its effectiveness in explaining change and maintenance of health behavior. According to health belief model, the high beliefs about Pap smear barriers cause negative behaviors in having the test. ${ }^{[20]}$ In regard to the methods of diagnosis for cervical cancer, many studies showed that many women indifferent countries underwent a Pap test at least once every two years. ${ }^{[21,22]}$ Within the present study, although about $60 \%$ of the sample were university and higher level of education, 34\% of the women didn't know about Pap smear, while 67.0\% had no Previous Pap Smear examination as well as had misconception regarding the risks that may lead to cervical cancers and the benefits of the screening and protective procedures which coincide with a study conducted in the United Arab Emirates (UAE), in which they assessed the knowledge, attitudes, and practices of UAE female primary care physicians regarding cervical screening, only $40 \%$ reported ever having performed a Pap smear. ${ }^{[23]}$

Although cervical cancer is both preventable and curable, most women in Saudi Arabia present at advanced stages that require extensive chemo-radiation therapy. This is due to the lack of the knowledge on cervical cancer and a proper screening program among Saudi women. There is a need to educate and promote awareness among Saudi women regarding cervical cancer screening and prevention. ${ }^{[16,24]}$

It is anticipated that in Saudi Arabia, as the population ages, there will be a dramatic increase in the incidence of cervical cancer. The estimated number of new cervical cancer cases and deaths in 2025 are 309 and 117, respectively. Thus screening and treatment of these precancerous lesions may be beneficial for preventing cervical cancer and related outcomes. The Ministry of Health of Saudi Arabia guideline panel (2014) recommended to use HPV test followed by colposcopy to screen for CIN2+ in women at risk of cervical cancer. ${ }^{[25]}$ About $48 \%$ of the women in the current study reported that referral for screening should be on physician request, while $66 \%$ of them didn't know the proper time for screening. HPV vaccination, recommended for young women as it has the potential to significantly reduce the rate of cervical cancer worldwide. Early studies show that vaccination reduces precancerous cervical lesions and corresponding referrals for colposcopy and cervical procedures. ${ }^{[26,27]}$ The majority of the women in the present study (96\%) didn't know about that vaccine. Counseling helps to reduce anxiety as well as protect the rights of the individual to health information.

Counseling should be directed toward addressing specific locally held fears and misconceptions such as fears of a possible outcome of cervical cancer diagnosis and the perceived effects of procedures on future childbearing .Prescreening counseling could help increase compliance with screening. To increase informed uptake, the tailored intervention should include information on the likely Harms and risks, as well as the benefits of screening. ${ }^{[1,22]}$ The Women's beliefs about factors help early diagnosis of cervical cancer post counseling, results of the current study revealed that educational level, awareness for early detection of disease, Mass media are important factors for motivating the women to carry early detection procedures of the cervical cancer. Regarding post counselling protective practice from cervical cancer a high significant was observed related to Pap smear $(p=.001)$, and for take vaccine. A highly statistical significant observed regarding use of contraceptive as prescribed and treatment of genital tract infections but no statistical significant in relation to self-examination for vulva may be due to the psychological fear of the impact of positive test on their physical and social life which in agreement with a study conducted in the western region of Saudi Arabia. ${ }^{\text {[24] }}$

\section{Conclusion}

Knowing about the health beliefs is the first step for understanding health-promoting behaviors. Research scientists and healthcare professionals have a need to understand why and under what conditions and beliefs people have to take actions to prevent, detect, and treat diseases. Future research by nurses needed to understand how beliefs impact preventive health behaviors of women. If beliefs related to health behaviors can be identified, nursing interventions for change of attitude could be developed, and hopefully increase desirable health outcomes.

\section{ACKNOWLEDGEMENTS}

The authors are thankful to the Deanship of Scientific Research, College of Nursing Research Center at King Saud University for funding this research.

\section{CONFlicts OF INTEREST Disclosure}

The authors declare that there is no conflict of interest. 


\section{REFERENCES}

[1] Wong LP, Wong YL, Low WY, et al. Knowledge and awareness of cervical cancer and screening among Malaysian women who have never had a Pap smear: a qualitative study. Singapore Medicine Journal. 2009; 50(1): 49-53. PMid:19224084

[2] Reis N, Bebis H, Kose S, et al. Knowledge, Behavior and Beliefs Related to Cervical Cancer and Screening among Turkish Women. Asian Pacific J Cancer Prev. 2012; 13: 1463-1470. http: //dx.doi.org/10.7314/AP JCP. 2012.13.4.1463

[3] Carr KC, Sellors JW. Cervical cancer screening in low resource settings using visual inspection with acetic acid. Journal of Midwifery and Women's Health care. 2004; 49(4): 329-37. PMid:15236713 http://dx.doi.org/10.1016/j.jmwh.2004.02.015

[4] The American College of Obstetricians and Gynecologists New guidelines issued in March. 2012.

[5] World Health Organization. Cervical Cancer Screening in Developing Countries. A report of WHO Consultation. World Health Organization, Geneva. 2005.

[6] Mosavel M, Simon C, Oakar C, et al. Cervical cancer attitudes and beliefs-a Cape Town community responds on World Cancer Day. Journal of Cancer Education. 2009; 24: 114-9. PMid:19431027 http://dx.doi.org/10.1080/08858190902854590

[7] Bhatla N, Joseph E. Cervical cancer prevention \& the role of human papillomavirus vaccines in India Indian Journal of Medical Research. 2009.

[8] Saslow D, Runowicz CD, Solomon D, et al. American Cancer Society guideline for the early detection of cervical neoplasia and cancer. Cancer Journal of Clinic. 2002; 52: 342-362. http: //dx . doi . org /10.3322/canjclin.52.6.342

[9] Patnick J. Cervical cancer screening in England. European Journal of Cancer. 2000; 36: 2205-2208. http://dx.doi.org/10.1016 /S0959-8049(00)00310-5

[10] World Health organization. Comprehensive cancer control. A Guide to Essential Practice. World Health Organization. Geneva. 2006.

[11] Ndikom CM, et al. Pre-screening counseling in cervical cancer prevention: Implications for nursing. International Journal of Nursing and Midwifery. 2011; 3(10): 158-164.

[12] Abotchie PN, Shokar NK. Cervical cancer screening among college students in Ghana: Knowledge and health beliefs. International Journal of Gynecologic Cancer. 2009; 19(3): 412-416. PMid:19407569 http://dx.doi.org/10.1111/IGC.0b013e3181a1d6de

[13] Kochroo S, Etzel CJ. Decreasing the cancer burden in developing countries: Concerns and recommendations. European Journal of Cancer Care. 2009; 18: 18-21. PMid:19473221 http://dx.doi.org /10.1111/j.1365-2354.2008.00985.x

[14] Mupepi SC, Sampselle CM, Johnson TRB. Knowledge, attitudes, and demographic factors influencing cervical cancer screening behavior of Zimbabwean women. Journal of Women's Health. 2011; 20: 943-952. PMid:21671779 http://dx.doi.org/10.1089/jwh. 2 010.2062

[15] Saudi Cancer Registry cancer incidence and survival reports Saudi Arabia. National Saudi Cancer Registry. Riyadh (KSA): Ministry of
Health. 2007. Available from: http://www.scr.org.sa/repor ts/SCR2007.pdf

[16] Khalid H. Attitudes, knowledge, and practices in relation to cervical cancer and its screening among women in Saudi Arabia, Saudi Med J. 2009; 30(9): 1208-1212.

[17] Dania AJ, Tasnim H. Prevalence of abnormal cervical cytology among subfertile Saudi women. 2010. Available from: http: //www . saudiannals . net/article. asp? issn=0256494 7 ; year $=2010$; volume $=30 ;$ is sue $=5 ;$ spage $=397$; epage $=400$; aulast $=\mathrm{Al}-\mathrm{Jaroudi}$

[18] Ackerson K, Gretebeck K. Factors influencing cancer screening practices of underserved women. Journal of American Academic Nurse and Practice. 2007; 19: 591-601. PMid:17970859 http: //dx.doi.org/10.1111/j.1745-7599.2007.00268.x

[19] Lee EE, Fogg L, Menon U. Knowledge and beliefs related to cervical cancer and screening among Korean American Women. Western Journal of Nursing Research. 2008; 30: 960-74. PMid:18539883 http://dx.doi.org/10.1177/0193945908319250

[20] Guvenc G, Akyuz A, Açikel CH. Health Belief Model Scale for Cervical Cancer and Pap Smear Test: psychometric testing. Journal of Advanced Nursing. 2010. PMid:20946564

[21] Brotto LA, Chou AY, Singh T, et al. Reproductive health practices among Indian, Indo-Canadian, Canadian East Asian, and EuroCanadian women: the role of acculturation. Journal of Obstetric and Gynecological Can. 2008; 30: 229-38. http://dx.doi.org/1 $0.1016 / \mathrm{S} 1701-2163$ (16)32759-1

[22] Sabrina CH, Chang BA, Jane ST, et al. A Questionnaire Study of Cervical Cancer Screening Beliefs and Practices of Chinese and Caucasian Mother-Daughter Pairs Living in Canada. Journal of Obstetric Gynecology Can. 2010; 32(3): 254-262. http://dx.doi .org/10. 1016/S1701-2163 (16) 34452-8

[23] Badrinath P, Ghazal-Aswad S, Osman N, et al. A study of knowledge, attitude, and practice of cervical screening among female primary care physicians in the United Arab Emirates. Health Care Women Int. 2004; 25: 663-660. PMid:15487484 http://dx.doi.org/10.10 80/07399330490458079

[24] Bondagji NS, Gazzaz FS, Sait K, et al. Prevalence of high-risk human papillomavirus infections in healthy Saudi women attending gynecologic clinics in the western region of Saudi Arabia, Ann Saudi Medical. 2013; 33(1): 13-17. PMid:23458934

[25] Sagr EDr. Al Kushi A, SalemH, et al. Clinical Practice Guideline on the Screening and Treatment of Precancerous Lesions for Cervical Cancer Prevention, The Saudi Center for EBHC Clinical Practice Guideline. 2014.

[26] Paavonen J, Naud P, Salmeron J, et al. Efficacy of human papillomavirus against cervical infection and pre-cancer caused by oncogenic HPV types. Lancet. 2009. http://dx.doi .org/10.1016/S 0140-6736 (09) 61248-4

[27] Chigbu CO, Aniebue UU. Non-uptake of colposcopy in a resourcepoor setting. International Journal of Gynecology and Obstetrics. 2011; 113(2): 100-102. PMid:21349518 http://dx.doi.org/10. 1016/j.ijgo.2010.11.017 